\title{
Meta-analysis confirms BCL2 is an independent prognostic marker in breast cancer
}

\author{
Grace M Callagy*1, Mark J Webber ${ }^{1}$, Paul DP Pharoah ${ }^{2}$ and Carlos Caldas ${ }^{3}$
}

\begin{abstract}
Address: ${ }^{1}$ Department of Pathology, National University of Ireland, Galway, Clinical Science Institute, Costello Road, Galway, Ireland, ${ }^{2}$ Cancer Research-UK Department of Oncology, Cancer Research-UK Genetic Epidemiology Unit and EPIC, Strangeways Research Laboratory, Worts Causeway, Cambridge CB1 8RN, UK and ${ }^{3}$ Department of Oncology, University of Cambridge and Cancer Research-UK Cambridge Research Institute, Li Ka Shing Centre, Cambridge CB2 ORE, UK
\end{abstract}

Email: Grace M Callagy* - grace.callagy@nuigalway.ie; Mark J Webber - mark.webber@nuigalway.ie; Paul DP Pharoah - paul1@srl.cam.ac.uk; Carlos Caldas - cc234@cam.ac.uk

* Corresponding author

Published: 29 May 2008

BMC Cancer 2008, 8:153 doi:10.1186/147|-2407-8-153
Received: 14 November 2007

Accepted: 29 May 2008

This article is available from: http://www.biomedcentral.com/I47I-2407/8/I53

(C) 2008 Callagy et al; licensee BioMed Central Ltd.

This is an Open Access article distributed under the terms of the Creative Commons Attribution License (http://creativecommons.org/licenses/by/2.0), which permits unrestricted use, distribution, and reproduction in any medium, provided the original work is properly cited.

\begin{abstract}
Background: A number of protein markers have been investigated as prognostic adjuncts in breast cancer but their translation into clinical practice has been impeded by a lack of appropriate validation. Recently, we showed that BCL2 protein expression had prognostic power independent of current used standards. Here, we present the results of a meta-analysis of the association between BCL2 expression and both disease free survival (DFS) and overall survival (OS) in female breast cancer.

Methods: Reports published in 1994-2006 were selected for the meta-analysis using a search of PubMed. Studies that investigated the role of BCL2 expression by immunohistochemistry with a sample size greater than 100 were included. Seventeen papers reported the results of 18 different series including 5,892 cases with an average median follow-up of 92.1 months.

Results: Eight studies investigated DFS unadjusted for other variables in 2,285 cases. The relative hazard estimates ranged from $0.85-3.03$ with a combined random effects estimate of $1.66(95 \% \mathrm{Cl}$ I.25 - 2.22). The effect of BCL2 on DFS adjusted for other prognostic factors was reported in II studies and the pooled random effects hazard ratio estimate was $1.58(95 \% \mathrm{Cl} 1.29-1.94)$. OS was investigated unadjusted for other variables in eight studies incorporating 3,910 cases. The hazard estimates ranged from $0.99-4.3 \mathrm{I}$ with a pooled estimate of risk of $1.64(95 \% \mathrm{Cl} 1.36-2.0)$. OS adjusted for other parameters was evaluated in nine series comprising 3,624 cases and the estimates for these studies ranged from I. 10 to 2.49 with a pooled estimate of $1.37(95 \% \mathrm{Cl}$ I.I I.58).

Conclusion: The meta-analysis strongly supports the prognostic role of BCL2 as assessed by immunohistochemistry in breast cancer and shows that this effect is independent of lymph node status, tumour size and tumour grade as well as a range of other biological variables on multi-variate analysis. Large prospective studies are now needed to establish the clinical utility of BCL2 as an independent prognostic marker.
\end{abstract}




\section{Background}

Breast cancer is a heterogenous disease whose behaviour is determined by the molecular characteristics of the tumour. In clinical practice, we rely on clinico-pathological features to predict tumour behaviour and patient outcome. These are powerful independent prognosticators $[1,2]$ but are imperfect and represent only crude measures of the biological behaviour of a tumour. The power of these factors can be increased when they are used in combination e.g. the Nottingham Prognostic Index (NPI) [1] but they cannot predict outcome for all patients [3-5] and, as a result, many patients receive unnecessary treatment.

In the last 30 years, intensive efforts have been made to identify tools to improve prognostication. These range from biological markers to computer-based algorithms such as ADJUVANT! [6] that incorporate clinico-pathological and biological features. Early immunohistochemical studies identified a plethora of biological markers that can be triaged into categories based on the strength of evidence supporting their prognostic role [7]. However, twenty years on only steroid hormone receptors and HER2 are used in clinical practice. The translation of these results has in part been impeded by a lack of robustness of the original research findings. Many studies were small and false positives are the result of a combination of low statistical power and publication bias. Furthermore, many prognostic markers are correlated and small studies have limited power to show independence of effects of novel markers in multivariate analyses.

Prognostic gene-based signatures have been reported with the claim that they out-perform current standards $[8,9]$ although this has been questioned [10-12]. While promising, inconsistencies relating to quality control, tissue handling, sample size and data analysis need to be addressed before the clinical utility of gene-based prognostic signatures can be established. Two prospective clinical trials of prognostic gene signatures are now ongoing $[13,14]$ and, it is hoped, these will provide insight into the utility of widespread gene expression profiling as clinical tools.

A complementary approach uses a limited number of immunohistochemical markers as surrogates for the genebased signatures. The 'intrinsic subtypes' [15-17] have been reproduced repeatedly in this way and this methodology is likely to be a more realistic approach for routine diagnostic application [18-20]. In order to have clinical application, it is paramount that any marker shows good and poor prognostic groups independently of currently used standards or markers at stringent levels of statistical significance. With this in mind, we recently evaluated a panel of 13 biomarkers by immunohistochemistry (IHC) in a series of over 700 breast cancers and validated the findings in a second consecutive series of 983 cases on a tissue micro-array (TMA) [21]. The panel included proteins whose genes were differentially expressed in the intrinsic subsets defined by microarray profiling $[15,16]$. We expected that such a panel would have greater prognostic power than any one individual marker but the results showed otherwise: only the anti-apoptotic protein BCL2 was required to predict overall survival independent of traditional parameters in both series. Furthermore BCL2 added to the prognostic power of the NPI.

The BCL2 protein is a member of the bcl family that regulate apoptosis. Its tumorigenic potential has been demonstrated in animal models [22] and is supported by the finding of over-expression of BCL2 in a variety of tumours and in lymphomas in which BCL2 acts as an oncogene $[23,24]$. In many solid organ tumours, including breast cancer, BCL2 paradoxically appears to exert a tumour suppressor effect, where its expression is associated with favourable prognostic features e.g. low grade, oestrogen receptor (ER)-positivity and good outcome [21]. This has been a consistent finding in most reports but the association with outcome was limited to univariate analysis in many.

The aim of this study was to evaluate the prognostic role of BCL2 in breast cancer by sytematically reviewing the available evidence. To this end, we identified all published reports that assessed the relationship between BCL2 and outcome in breast cancer and performed a meta-analysis using standard statistical techniques.

\section{Methods}

Reports investigating the prognostic role of BCL2 in breast cancer were selected for review using a search of PubMed from 1994-2006 using the following criteria: '(bcl-2 and breast) AND (prognosis* [Title/Abstract] OR (first [Title/ Abstract] AND episode [Title/Abstract]) OR cohort [Title/ Abstract])' and also '(bcl-2 and breast) AND (incidence [MeSH:noexp] OR mortality [MeSH Terms] OR follow up studies [MeSH:noexp] OR prognos* [Title/Abstract] OR predict* [Title/Abstract] OR course* [Text Word])' limited to the English language. Three hundred and thirty three citations were retrieved. Eligible reports were those that examined the association between expression of BCL2 by IHC and either overall survival (OS) and/or disease free survival (DFS) in a clinical series of invasive breast cancer. Reports considered ineligible for the meta-analysis were reviews; those of in situ carcinoma or precursor lesions or of only male breast cancer; those that used cell lines or techniques other than IHC; and reports where either OS or DFS were not used as clinical endpoints; or where the association between another marker and outcome was being examined and data for BCL2 was not presented. Authors that published multiple reports on a single series 
were included once. The bibliography of the reports was also searched by hand.

Fifty-three eligible studies were identified. Small studies are more prone to publication bias and failure to report a hazard ratio (HR) can be taken as an indicator of study quality [25]. We therefore included the seventeen studies that were based on at least 100 patients and had also reported an estimate of the HR [21,26-41]. The remaining 36 reports (Additional files 1 and 2) included 11 reports that were either based on a small number of cases $(\leq 100)$ or were larger studies that did not report a HR but did provide sufficient data to estimate the HR according to the method of Parmer et. al. [42]. These were analysed separately to determine if these studies would introduce significant bias [43-53]. The remaining 25 studies, including nine using small series, provided insufficient data for analyses and were excluded (Additional files 1 and 2).

\section{Design of the meta-analysis}

Pooled estimates of the HRs were obtained using both fixed-effect and random-effects meta-analysis using the inverse-variance weighting method based on published confidence intervals for the HRs [54]. For those studies that did not report the HR but did provide sufficient information on survival by BCL2 status the we estimated the $\mathrm{HR}$ and confidence intervals according to the method of Parmer et al. [42].

In one report [27], the upper confidence limit for the univariate HR was clearly incorrect and inconsistent with the lower confidence limit. The variance for this HR was estimated based on the lower confidence limit only. Statistical heterogeneity between studies was assessed using the among-study variance (s2) and the statistic I2 [55]. A funnel plot and Egger's regression test for funnel plot asymmetry [56] were used to look for the presence of a smallstudy effect that might be due to publication bias.

In many studies, in addition to univariate analysis, the risks were adjusted for other prognostic factors. We performed separate analyses based on adjusted and unadjusted HRs for both DFS and OS. For the purposes of the analysis we converted all hazard ratios to a comparison of BCL2 negative tumours with BCL2 positive tumours.

All analyses were carried out using Stata version 9 (Stata Corporation, College Station, TX, USA).

\section{Results}

Seventeen papers reporting 18 large case series with complete statistical data were included in the main analyses. These evaluated the role of BCL2 as a predictor of OS or DFS in 5,892 cases of breast cancer (Additional files 3 and 4). Median follow-up ranged from 0.2 to 472 months (average 92.1 months). In total, 2,619 cases of node-negative disease and 3,963 cases of node-positive disease were analysed. In 333 cases, nodal status was either unknown or not indicated. Five of the 18 series comprised consecutive cases unselected for specific characteristics $[21,29,31,33,39]$. The remainder consisted of cases that were either accrued onto clinical trials $[21,32,35,37]$ or selected according to defined eligibility criteria i.e. nodenegative $[30,41]$ or node-positive $[26,28,34,36,38,40]$ disease, or tumour size [27]. Unfortunately, the number of studies was too small for formal meta-analysis for each of these end-points.

Fourteen studies reported on the effect of BCL2 on DFS of which three reported only unadjusted $[32,34,40]$ and six reported only multivariate adjusted $[29,30,33,36,37,39]$ hazards and five reported both $[26,27,35,38,41]$. Where multivariate analysis was performed the parameters included varied. Clinico-pathological variables were incorporated in most analyses with the following exceptions. Tumour size was excluded in two reports $[35,37]$. Nodal status was omitted in five studies $[26,30,35,37,41]$ although these were selected series that consisted entirely of either node positive [26], node negative [30,41] or metastatic disease $[35,37]$. Tumour grade was also excluded in five reports $[26-28,37,38]$. The other biomarkers assessed varied with the exception of steroid hormone receptor status, which was incorporated in the majority of analyses (except $[27,29]$ ). p53 was included as a co-variable in 11 studies $[21,26-28,31-34,37,39,40]$ and HER2 in three $[21,26-28,31-34,37,39,40]$. A monoclonal antibody to assess BCL2, either from Dako (Clone 124) [21,26-28,31$34,37,39,40]$, Novacastra [29] or Dakopatts [30,36,38,41] was used by most investigators. A polyclonal antibody was used in one study [35]. Cytoplasmic staining was scored using a dichotomous scoring system in all studies with a cut-off for positive status between $10 \%$ and $40 \%$. Berardo et al. [34] applied both continuous and dichotomous system and showed that the former was associated with independent significance but not the latter.

Eight studies including 2,285 patients reported the effect of BCL2 expression on DFS in analyses unadjusted for other risk factors (Figure 1, Table 1). The unadjusted HR estimates for DFS from these studies ranged from 0.85 3.03 and all but one of these was significant at a nominal $p<0.05$. The pooled random effects estimate was 1.66 $(95 \% \mathrm{CI}=1.25-2.22)$. However, there was evidence for significant heterogeneity amongst the studies $(\mathrm{Q}=22.4,7$ degrees of freedom (df), $p=0.002$ ), which might be expected given the difference in populations being studied and experimental methods used. Five studies $[26,34,35,38,41]$ included node-positive disease only accounting for 1,659 cases. Notwithstanding that, the heterogeneity was largely due to the study reported by Mot- 
Table I: Results of meta-analysis of expression of Bcl-2 and outcome in Breast Cancer.

\begin{tabular}{|c|c|c|c|c|c|}
\hline \multirow[t]{2}{*}{ Endpoint and meta-analysis model } & & \multicolumn{2}{|c|}{ Estimate of Relative Hazard } & \multicolumn{2}{|c|}{ Homogeneity Test } \\
\hline & & $(95 \% \mathrm{Cl})$ & p & $Q(d f)$ & $\mathrm{P}$ \\
\hline \multicolumn{6}{|c|}{ Unadjusted Disease-Free Survival (8 studies, $n=2285$ ) } \\
\hline Fixed & 1.5 & $(1.3-1.7)$ & $<0.001$ & $22.4(7)$ & 0.002 \\
\hline Random & 1.7 & $(1.3-2.2)$ & $<0.001$ & & \\
\hline Fixed $*$ & 1.7 & $(1.5-2.0)$ & $<0.001$ & $6.6(6)$ & 0.360 \\
\hline Random* & 1.7 & $(1.5-2.1)$ & $<0.001$ & & \\
\hline \multicolumn{6}{|c|}{ Adjusted Disease-Free Survival (I I studies, $n=2128$ ) } \\
\hline Fixed & 1.5 & $(1.3-1.7)$ & $<0.001$ & $17.2(10)$ & 0.07 \\
\hline Random & 1.6 & $(1.3-2.0)$ & $<0.001$ & & \\
\hline \multicolumn{6}{|c|}{ Unadjusted Overall Survival ( 8 studies, $n=3910$ ) } \\
\hline Fixed & 1.6 & $(1.4-1.7)$ & $<0.001$ & $17.5(7)$ & 0.015 \\
\hline Random & 1.6 & $(1.4-2.0)$ & $<0.001$ & & \\
\hline Fixed $*$ & 1.6 & $(1.5-1.8)$ & $<0.001$ & $10.0(6)$ & 0.126 \\
\hline Random* & 1.7 & $(1.5-2.0)$ & $<0.001$ & & \\
\hline \multicolumn{6}{|c|}{ Adjusted Overall Survival ( 9 studies, $n=3624$ ) } \\
\hline Fixed & 1.3 & $(1.2-1.4)$ & $<0.001$ & $15.5(8)$ & 0.050 \\
\hline Random & 1.4 & $(1.2-1.6)$ & $<0.001$ & & \\
\hline
\end{tabular}

* values after exclusion of the study by Motolesse et al. $[31](n=157)$

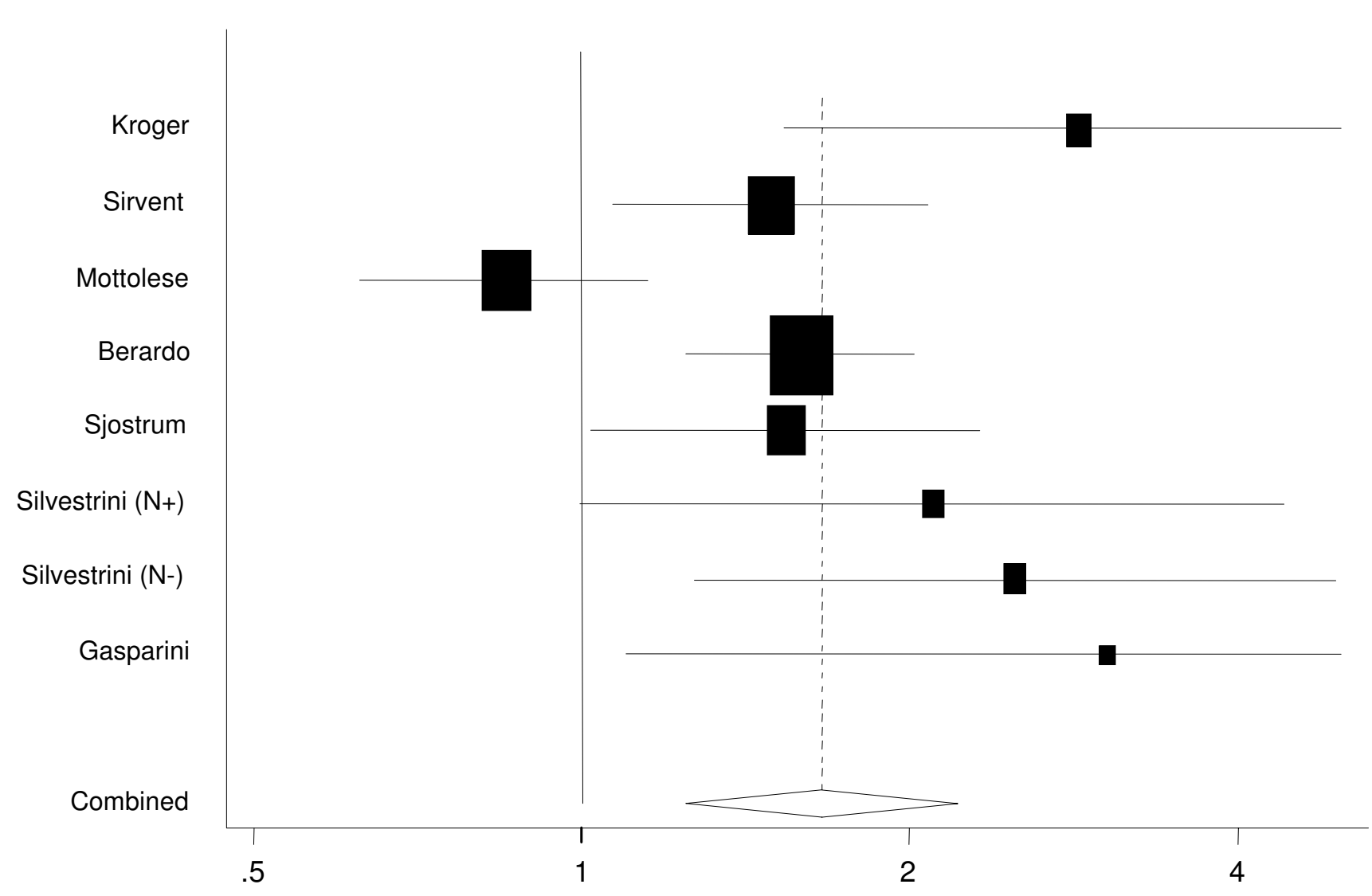

Figure I

Funnel plot of the combined relative hazard from the random effects models for disease free survival in BCL2 negative cases compared to BCL2 positive cases in univariate analysis. 
tolese et al. [32], which was the only study to report a better outcome for BCL2 negative tumours. After the exclusion of the latter, the pooled estimate of HR was 1.74 $(95 \% \mathrm{CI}=1.46-2.07)$ with no significant heterogeneity $(\mathrm{Q}=6.6,6 \mathrm{df}, p=0.36)$. There was no evidence for publication bias $(p=0.14)$. Eight studies were excluded from the primary analysis because they were small or because the HR was not reported but could be estimated from the data presented $[43-48,52,53]$. The pooled HR for these studies was $2.11(95 \% \mathrm{CI}=1.62-2.77)$. This is significantly different from the estimate for the other studies ( $p$ $=0.02$ ) suggesting, as predicted, a substantial bias in the HR estimates for the smaller studies and those with less completely reported data. If, however, all studies were analysed together the pooled HR estimate was 1.59 $(95 \% \mathrm{CI}=1.41-1.81)$.

Eleven studies including 2,105 patients reported the effects of BCL2 on DFS adjusted for other prognostic factors $[26,27,29,30,33,35-39,41]$ (Table 1). The adjusted HR estimates were generally close to one but ranged from 1.10 to 3.26 . In five of these studies incorporating 950 cases, BCL2 was an independent predictor of DFS. The pooled random effects HR estimate for these studies was $1.58(95 \% \mathrm{CI}=1.29-1.94)$ without evidence for significant heterogeneity between the studies $(\mathrm{Q}=17.2,10 \mathrm{df}, p$ $=0.07)$ or publication bias $(p=0.78)$. Four of the studies that failed to show an independent association between BCL2 and DFS used the Dakopatts or a polyclonal antibody.

The effect of BCL2 expression on OS was evaluated in 12 studies in 11 reports (Table 1). HRs were unadjusted in three of these $[32,34,40]$ and adjusted for other variables in four $[28,36,37,39]$ and both unadjusted and adjusted HRs were given in four other reports $[21,27,31,41]$. The eight studies from seven reports $[21,27,31,41]$ incorporating 3,910 cases where the expression of BCL2 was unadjusted for other variables produced hazard estimates ranging from 0.99-4.31 (Figure 2), of which 6 were statistically significant with a pooled estimate of risk of 1.64 $(95 \% \mathrm{CI}=1.36-1.97)$. There was evidence of statistical heterogeneity $(\mathrm{Q}=17.5,7 \mathrm{df}, p=0.015)$ that again was virtually entirely due to the contribution of the report by

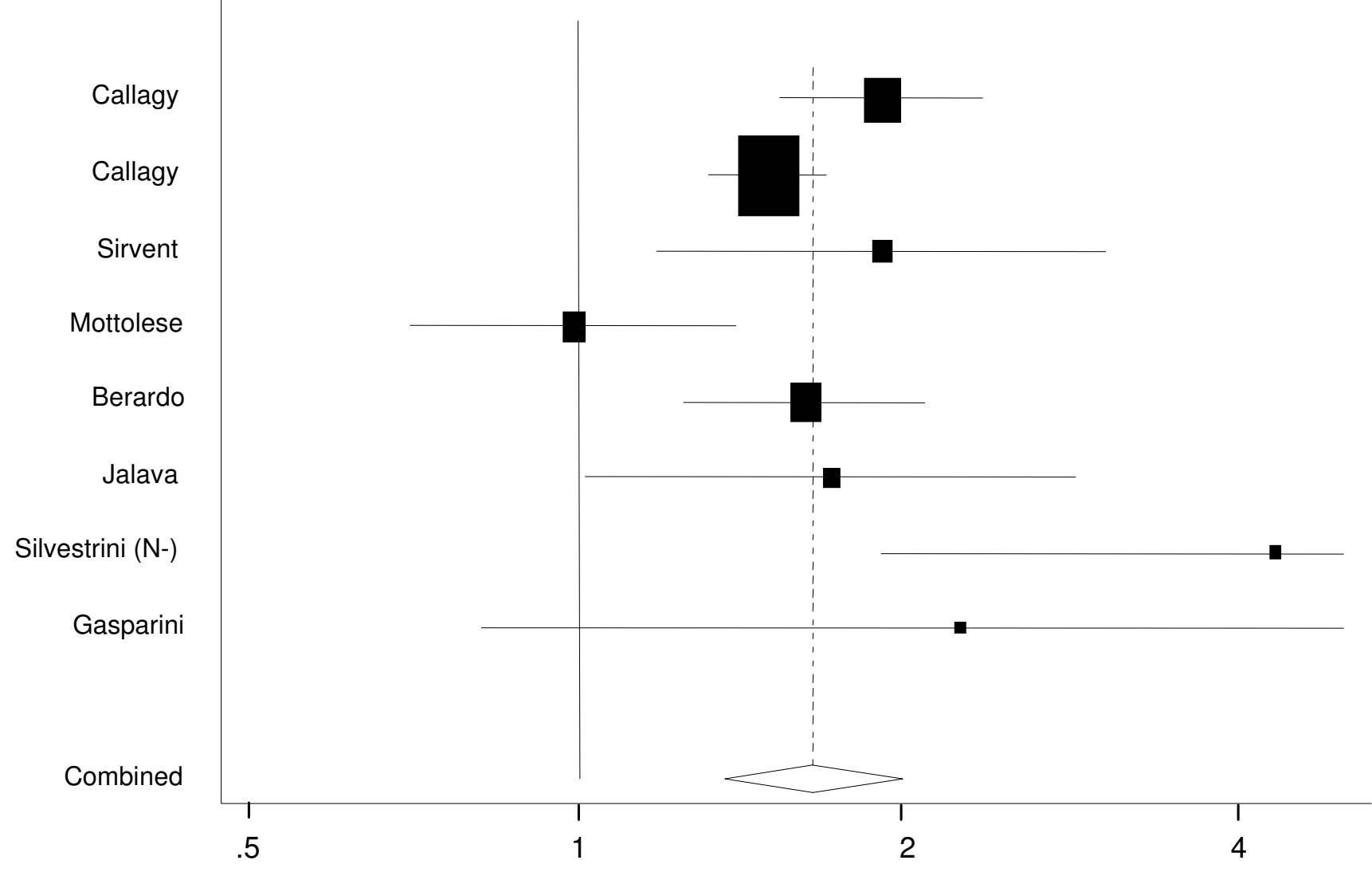

Figure 2

Funnel plot of the combined relative hazard from the random effects models for overall survival for BCL2 negative cases compared to BCL-2 positive cases in univariate analysis. 
Mottolese et al. After exclusion of this study there was little change in the HR (pooled estimate 1.73, 95\% $\mathrm{CI}=1.48$ 2.02) and no evidence for heterogeneity $(\mathrm{Q}=9.98,6 \mathrm{df}, p$ $=0.13)$ or publication bias $(p=0.87)$.

Six studies were excluded from the primary analysis because they were small or because the HR was not reported but could be estimated from the data presented [44,48-52]. The pooled HR for these studies was 3.42 $(95 \% \mathrm{CI}=2.41-4.86)$. This is significantly different from the estimate for the other studies $(p<0.001)$, again suggesting a substantial bias in the HR estimates for the smaller studies. If, however, all studies were analysed together the pooled HR estimate was $1.99(95 \% \mathrm{CI}=1.62$ $-2.45)$.

Nine series comprising 3,624 cases were used for the meta-analysis of the expression of BCL2 on OS adjusted for other parameters $[21,27,28,31,36,37,39,41]$. BCL2 was an independent predictor of outcome in four of these $[21,36,39]$ totalling 2,190 cases. A narrow range of estimates was observed from 1.10 to 2.49 with a pooled estimate of $1.37(95 \% \mathrm{CI}=1.19-1.58)$. There was borderline evidence of heterogeneity between the studies $(\mathrm{Q}=15.48$, $8 \mathrm{df}, p=0.05)$ and evidence of publication bias $(p=$ 0.022 ).

\section{Discussion}

The published data incorporating 5,892 cases strongly support the prognostic role of BCL2 as assessed by IHC in breast cancer showing that it is associated with both DFS and OS (pooled HR estimates of 1.66 and 1.64 respectively). These effects were slightly attenuated but still significant in multivariate analyses (adjusted HRs of 1.58 and 1.37 for DFS and OS respectively), showing that this effect is independent of lymph node status, tumour size and tumour grade as well as a range of other biological variables on multivariate analysis.

It is possible that the result of the meta-analysis could have been influenced by differences between the 18 studies. The finding of study heterogeneity in HR estimates is unsurprising and, even though the study by Mottolese et al. accounted for much of the heterogeneity for DFS, there were substantial differences between the other studies that could have influenced the result. Different cohorts of patients and treatment regimes were used. Five studies used unselected consecutive series $[21,29,31,33,39]$ and these patients were managed according to standard treatment protocols. In all of these reports, BCL2 was an independent predictor of either DFS $[29,33,39]$ or OS $[21,31,39]$ on multivariate analyses. Treatments varied where cases were part of a clinical trial $[21,26,32,35,37]$ although BCL2 was still an independent predictor of DFS and $O S$ in the majority $([26,37]$ and $[21,37]$ respectively).
The cause of the heterogeneity from the study of Mottolese et al. is unclear. The series was part of a clinical trial that examined the influence of a number of patho-biological factors on response to adjuvant therapy. Patient characteristics, type of antibody and scoring system were similar to those used by others [21]. However, the authors showed an association between BCL2 positivity and adverse outcome, which is at variance with most other published reports and with all others included in the meta-analysis.

The types of antibodies employed and cut-offs used to define immunohistochemical positivity also varied between reports. The effect of each of these is difficult to assess but could have contributed to the observed heterogeneity. Clone 124 was the most commonly used and was used in the majority of studies where BCL2 was an independent predictor of DFS or OS [21,26$28,31,33,37,39,40]$. In contrast, most reports that used the Dakopatts monoclonal antibody or a polyclonal antibody $[30,35,36,41]$ failed to show a statistically significant association with DFS or OS, although the direction of effect was the same. There was little difference in the scoring systems between the studies although the different cut-off points varied from $10 \%$ to $40 \%$. The inclusion of different combinations of variables in multivariate analyses could also have affected the results of a pooled estimate of the adjusted HRs. The purpose of the metaanalysis was to establish if the association of BCL2 with prognosis is independent of other confounders. The majority of studies included the most important variables in their analysis, which suggests that the pooled adjusted estimate of hazard is robust and supports BCL2 as an independent risk factor. In addition, the similarity between the HRs observed for BCL2 in both univariate and multivariate analyses, where both types of analyses were performed also attest to its prognostic role.

The effect of bias on the meta-analysis should also be considered. Seventeen eligible reports provided data suitable for the meta-analysis. Thirty six eligible studies were excluded, including studies using small series and those that did not provide minimum data for the pooled analysis. The exclusion of small studies may have minimised the effect of publication bias - the non-publication of studies with null results - by not including reports of small series that are more likely to be published if they show a positive result. This is supported by our findings that the HRs reported by smaller studies were systematically larger than those reported by the larger studies. The inclusion of only large studies and those that meet minimum quality criteria in the meta-analysis maximised the chance of the pooled estimate of HR representing the true HR. Whether we have been able to retrieve all relevant reports in the literature is unclear. In particular, it is possi- 
ble that our search strategy will have missed studies evaluating BCL2 as one of multiple markers, but where no association with outcome was detected. This is perhaps most likely to occur in studies using TMAs. However, if large negative studies had been missed, a substantial degree of publication bias (perhaps a misnomer here as the data may be published and not retrieved) would have been detected, whereas we found little evidence for this. It seems unlikely that missing data bias either through nonpublication, or through failure to identify and retrieve the data, would have led to a substantial overestimation of the meta-analysis HR estimates.

The mechanisms through which BCL2 might exert its protective effect in breast cancer are unclear. Whether it is consequent upon its role in apoptosis or whether nonapoptotic functions are involved is unknown. The antiapoptotic role of BCL2 is well characterised but its function in cell cycle control has received less attention. The latter is well supported by cell line studies that show BCL2 expression delays G1 progression and G1-S transition by prolonging G0 and is capable of growth inhibitory effects analogous to those of p53 [24,57]. It is postulated that the dominance of one of these functions over another may depend on the cell type and physiology and that the antiproliferative effect translates into a tumour suppressor role in solid epithelial tumours including breast cancer. Furthermore, it remains to be established if other proteins e.g. Wnt11 [58] or bcl homologues potentiate the tumour suppressor role of BCL2 in breast cancer. At least $20 \mathrm{bcl}$ proteins are known that may act in a synergistic manner, analogous to the co-operative effect of MYC and BCL2 in lymphomagenesis.

The therapeutic implication of our findings and how BCL2 might improve prognostication and/or selection of patients for treatment remain to be determined. The data presented here shows that BCL2 has the potential to improve patient stratification and guide patient management. Currently, patients are stratified into different treatment categories based primarily on nodal status, tumour size, tumour grade, receptor status, patient age and, to a lesser extent, tumour type. A range of guidelines e.g. St. Gallen, National Institutes of Health Consensus Development Panel, National Comprehensive Cancer Network (NCCN) Clinical Practice Guidelines and prognostic systems e.g. NPI, ADJUVANT! are used internationally, each of which combines these features in different ways to assign patients to risk categories. Recommendations for systemic treatment are made by some, for example, the NCCN recommends adjuvant chemotherapy for tumours $>1 \mathrm{~cm}$ in combination, with adjuvant hormonal and traztuzumab depending on receptor status, but not for small ( $\leq 5 \mathrm{~mm})$, node-negative invasive tumours or for nodenegative grade 1 tumours between $6 \mathrm{~mm}$ and $1 \mathrm{~cm}$. In the
UK, the NPI is used widely to inform decisions on adjuvant therapy $[59,60]$, however, there is no agreement on cut-off values. The prognostic value of the NPI is supported from validation studies but no new prognostic factors have been shown that add substantially to its use. Taken in conjunction with previous data, our results suggest that BCL2 could improve the stratification of patients by the NPI and could separate both the moderate and the poor prognostic groups each into two prognostic categories. We showed previously that the prognostic effect of BCL2 status is maximal in the first five years after a diagnosis of breast cancer and wanes thereafter, suggesting that its utility as a diagnostic adjunct may be limited to this period. Even if BCL2 were to be used in clinical decision making, the most appropriate cut-off used to assign positivity is uncertain. Our previous report [21] indicated that a dichotomous scoring system using a 10\% cut-off provided the most parsimonious fit for predicting overall survival using a cox regression analysis, but published data are insufficient to replicate this.

The number of studies included in the meta-analysis with different treatment endpoints was too small to perform a meaningful analysis of its predictive role. However, there is an emerging consensus that BCL2 plays a key role in determining response to endocrine therapy and chemotherapy [61]. BCL2 is an oestrogen responsive gene $[58,62]$ and many clinical studies have shown an association with favourable response to endocrine therapy $[40,61,63]$. BCL2 is a component of the 21-gene signature used to predict recurrence in tamoxifen-treated ER-positive node-negative breast cancer and its role is being evaluated prospectively in the TAILORx trial [14].

\section{Conclusion}

In summary, we have shown that BCL2 is an independent prognostic marker in two large series of breast cancer [21] and, here, provide an estimate of the average size of this association with outcome in a meta-analysis on 16 other series totalling over 5,000 patients. Using this approach, we have demonstrated the prognostic power of a single marker in breast cancer. Large studies, both observational cohorts and clinical trials, are now urgently needed to test whether BCL2 and multiple other markers can provide prognostic information in addition to currently used standards and also to establish if BCL2 has clinical utility.

\section{List of abbreviations}

CI: confidence interval; df: degrees of freedom; DFS: disease free survival; EC: epirubicin and cyclophosphamide; G-CSF: granulocyte colony stimulating factor; HER2: Human epidermal growth factor receptor; HR: hazard ratio; IHC: immunohistochemistry; NCCN: National Comprehensive Cancer Network; NPI: Nottingham Prognostic Index; OS: overall survival; TAILORx: Trial Assign- 
ing Individualized Options for Treatment (Rx); TMA: tissue micro-array; TNM: tumour, nodal status, metastasis; UICC: Union Internationale Contre le Cancer.

\section{Competing interests}

The authors declare that they have no competing interests.

\section{Authors' contributions}

MJW performed the search of pubmed and organised the data. GMC organised the data, drafted and finalised the manuscript. PDPP performed the meta-analysis. PDPP and CC both contributed to writing and finalising of the manuscript. All authors read and approved the final manuscript.

\section{Additional material}

\section{Additional file 1}

Table of 36 studies excluded from the meta-analysis. table summarising the 36 studies excluded from the meta-analysis on the basis of small study size and the provision of insufficient data for the pooled analysis.

Click here for file

[http://www.biomedcentral.com/content/supplementary/1471-

2407-8-153-S1.xls]

\section{Additional file 2}

References for 36 studies excluded from meta-analysis. References for the 36 studies summarised in additional file 1 that were excluded from metaanalysis.

Click here for file

[http://www.biomedcentral.com/content/supplementary/14712407-8-153-S2.doc]

\section{Additional file 3}

Reports examining the association between expression of BCL2 and DFS and/or OS that include over 100 cases of breast cancer. table summarising the 17 reports included for the meta-analysis.

Click here for file

[http://www.biomedcentral.com/content/supplementary/14712407-8-153-S3.doc]

\section{Additional file 4}

Results of univariate and multivariate analyses for OS and DFS for 17 studies included in the meta-analysis. table summarising the results of univariate and multivariate analysis in 17 reports included for the metaanalysis.

Click here for file

[http://www.biomedcentral.com/content/supplementary/14712407-8-153-S4.doc]

\section{Acknowledgements}

The authors received no specific funding for this study.

\section{References}

I. Galea MH, Blamey RW, Elston CE, Ellis IO: The Nottingham Prognostic Index in primary breast cancer. Breast Cancer Res Treat 1992, 22(3):207-219.
2. Elston CW, Ellis IO: Pathological prognostic factors in breast cancer. I. The value of histological grade in breast cancer: experience from a large study with long-term follow-up. Histopathology 1991, I9(5):403-410.

3. Caldas C, Aparicio SA: The molecular outlook. Nature 2002, 4I5(687 I): 484-485.

4. Goldhirsch A, Glick JH, Gelber RD, Senn HJ: Meeting highlights: International Consensus Panel on the Treatment of Primary Breast Cancer. J Natl Cancer Inst 1998, 90(2I): I60 I-I608.

5. Eifel P, Axelson JA, Costa J, Crowley J, Curran WJ Jr., Deshler A, Fulton S, Hendricks CB, Kemeny M, Kornblith AB, Louis TA, Markman $M$, Mayer R, Roter D: National Institutes of Health Consensus Development Conference Statement: adjuvant therapy for breast cancer, November I-3, 2000. J Natl Cancer Inst 200I, 93( I 3):979-989.

6. Ravdin PM, Siminoff LA, Davis GJ, Mercer MB, Hewlett J, Gerson N, Parker HL: Computer program to assist in making decisions about adjuvant therapy for women with early breast cancer. J Clin Oncol 2001, I9(4):980-991.

7. Fitzgibbons PL, Page DL, Weaver D, Thor AD, Allred DC, Clark GM, Ruby SG, O'Malley F, Simpson JF, Connolly JL, Hayes DF, Edge SB, Lichter A, Schnitt SJ: Prognostic factors in breast cancer. College of American Pathologists Consensus Statement 1999. Arch Pathol Lab Med 2000, I 24(7):966-978.

8. van ' $t$ Veer LJ, Dai $H$, van de Vijver MJ, He YD, Hart AA, Mao M, Peterse HL, van der Kooy K, Marton MJ, Witteveen AT, Schreiber G], Kerkhoven RM, Roberts C, Linsley PS, Bernards R, Friend SH: Gene expression profiling predicts clinical outcome of breast cancer. Nature 2002, 4 I5(687I):530-536.

9. Wang Y, Klijn JG, Zhang Y, Sieuwerts AM, Look MP, Yang F, Talantov D, Timmermans M, Meijer-van Gelder ME, Yu J, Jatkoe T, Berns EM, Atkins D, Foekens JA: Gene-expression profiles to predict distant metastasis of lymph-node-negative primary breast cancer. Lancet 2005, 365(9460):67I-679.

10. Eden P, Ritz C, Rose C, Ferno M, Peterson C: "Good Old" clinical markers have similar power in breast cancer prognosis as microarray gene expression profilers. Eur J Cancer 2004, 40(12): 1837-184|.

II. Naderi A, Teschendorff AE, Barbosa-Morais NL, Pinder SE, Green AR, Powe DG, Robertson JF, Aparicio S, Ellis IO, Brenton JD, Caldas $C$ : A gene-expression signature to predict survival in breast cancer across independent data sets. Oncogene 2007, 26(10): $|507-15| 6$.

12. Teschendorff AE, Naderi A, Barbosa-Morais NL, Pinder SE, Ellis IO, Aparicio S, Brenton JD, Caldas C: A consensus prognostic gene expression classifier for ER positive breast cancer. Genome Biol 2006, 7( I 0):RIOI.

13. Bogaerts J, Cardoso F, Buyse M, Braga S, Loi S, Harrison JA, Bines J, Mook S, Decker N, Ravdin P, Therasse P, Rutgers E, van ' $t$ Veer LJ, Piccart $M$ : Gene signature evaluation as a prognostic tool: challenges in the design of the MINDACT trial. Nat Clin Pract Oncol 2006, 3(1 0):540-55I.

14. Sparano JA: TAILORx: trial assigning individualized options for treatment (Rx). Clin Breast Cancer 2006, 7(4):347-350.

15. Perou CM, Sorlie T, Eisen MB, van de Rijn M, Jeffrey SS, Rees CA, Pollack JR, Ross DT, Johnsen H, Akslen LA, Fluge O, Pergamenschikov A Williams C, Zhu SX, Lonning PE, Borresen-Dale AL, Brown PO, Botstein D: Molecular portraits of human breast tumours. Nature 2000, 406(6797):747-752.

16. Sorlie T, Perou CM, Tibshirani R, Aas T, Geisler S, Johnsen H, Hastie $T$, Eisen MB, van de Rijn M, Jeffrey SS, Thorsen T, Quist H, Matese JC, Brown PO, Botstein D, Eystein Lonning P, Borresen-Dale AL: Gene expression patterns of breast carcinomas distinguish tumor subclasses with clinical implications. Proc Natl Acad Sci U S A 2001, 98( I 9): I0869-10874.

17. Blenkiron C, Goldstein LD, Thorne NP, Spiteri I, Chin SF, Dunning MJ, Barbosa-Morais NL, Teschendorff AE, Green AR, Ellis IO, Tavare S, Caldas C, Miska EA: MicroRNA expression profiling of human breast cancer identifies new markers of tumour subtype. Genome Biol 2007, 8( I 0):R2 |4.

18. Callagy G, Cattaneo E, Daigo Y, Happerfield L, Bobrow LG, Pharoah PD, Caldas C: Molecular classification of breast carcinomas using tissue microarrays. Diagn Mol Pathol 2003, I 2(I):27-34.

19. Nielsen TO, Andrews HN, Cheang M, Kucab JE, Hsu FD, Ragaz J, Gilks CB, Makretsov N, Bajdik CD, Brookes C, Neckers LM, Evdokimova V, Huntsman DG, Dunn SE: Expression of the insulin-like 
growth factor I receptor and urokinase plasminogen activator in breast cancer is associated with poor survival: potential for intervention with 17-allylamino geldanamycin. Cancer Res 2004, 64(I):286-29I.

20. Makretsov NA, Huntsman DG, Nielsen TO, Yorida E, Peacock M, Cheang MC, Dunn SE, Hayes M, van de Rijn M, Bajdik C, Gilks CB: Hierarchical clustering analysis of tissue microarray immunostaining data identifies prognostically significant groups of breast carcinoma. Clin Cancer Res 2004, I (18 Pt I):6 |43-6I5I.

21. Callagy GM, Pharoah PD, Pinder SE, Hsu FD, Nielsen TO, Ragaz J, Ellis 10 , Huntsman $D$, Caldas $\mathrm{C}$ : Bcl-2 is a prognostic marker in breast cancer independently of the Nottingham Prognostic Index. Clin Cancer Res 2006, I 2(8):2468-2475.

22. McDonnell TJ, Korsmeyer SJ: Progression from lymphoid hyperplasia to high-grade malignant lymphoma in mice transgenic for the $\mathbf{t}(14 ; \mathbf{1 8})$. Nature 1991, 349(6306):254-256.

23. McDonnell TJ, Troncoso P, Brisbay SM, Logothetis C, Chung LW, Hsieh JT, Tu SM, Campbell ML: Expression of the protooncogene bcl-2 in the prostate and its association with emergence of androgen-independent prostate cancer. Cancer Res 1992, 52(24):6940-6944.

24. Pietenpol JA, Papadopoulos N, Markowitz S, Willson JK, Kinzler KW, Vogelstein B: Paradoxical inhibition of solid tumor cell growth by bcl2. Cancer Res 1994, 54(14):37| 4-37I7.

25. McShane LM, Altman DG, Sauerbrei W, Taube SE, Gion M, Clark GM: Reporting recommendations for tumor marker prognostic studies (REMARK). J Natl Cancer Inst 2005, 97( I6): I I80- I I 84.

26. Kroger N, Milde-Langosch K, Riethdorf S, Schmoor C, Schumacher $M$, Zander AR, Loning T: Prognostic and predictive effects of immunohistochemical factors in high-risk primary breast cancer patients. Clin Cancer Res 2006, I 2(I): 159-168.

27. Sirvent Jj, Aguilar MC, Olona M, Pelegri A, Blazquez S, Gutierrez C: Prognostic value of apoptosis in breast cancer (pTI-pT2). A TUNEL, p53, bcl-2, bag-I and Bax immunohistochemical study. Histol Histopathol 2004, 19(3):759-770.

28. Chang J, Clark GM, Allred DC, Mohsin S, Chamness G, Elledge RM: Survival of patients with metastatic breast carcinoma: importance of prognostic markers of the primary tumor. Cancer 2003, 97(3):545-553.

29. Yang Q, Sakurai T, Yoshimura G, Suzuma T, Umemura T, Nakamura M, Nakamura Y, Mori I, Kakudo K: Prognostic value of Bcl-2 in invasive breast cancer receiving chemotherapy and endocrine therapy. Oncol Rep 2003, I O(I): | $2|-| 25$

30. Kymionis GD, Dimitrakakis CE, Konstadoulakis MM, Arzimanoglou I, Leandros E, Chalkiadakis G, Keramopoulos A, Michalas S: Can expression of apoptosis genes, bcl-2 and bax, predict survival and responsiveness to chemotherapy in node-negative breast cancer patients? J Surg Res 200I, 99(2): I6I-I68.

31. Jalava PJ, Collan YU, Kuopio T, Juntti-Patinen L, Kronqvist P: Bcl-2 immunostaining: a way to finding unresponsive postmenopausal N+ breast cancer patients. Anticancer Res 2000, 20(2B): $1213-1219$.

32. Mottolese M, Benevolo M, Del Monte G, Buglioni S, Papaldo P, Nistico C, Di Filippo F, Vasselli S, Vici P, Botti C: Role of P53 and BCL2 in high-risk breast cancer patients treated with adjuvant anthracycline-based chemotherapy. I Cancer Res Clin Oncol 2000, I 26(I 2):722-729.

33. Le MG, Mathieu MC, Douc-Rasy S, Le Bihan ML, Adb El All H, Spielmann M, Riou G: c-myc, p53 and bcl-2, apoptosis-related genes in infiltrating breast carcinomas: evidence of a link between bcl-2 protein over-expression and a lower risk of metastasis and death in operable patients. Int / Cancer 1999, 84(6):562-567.

34. Berardo MD, Elledge RM, de Moor C, Clark GM, Osborne CK, Allred DC: bcl-2 and apoptosis in lymph node positive breast carcinoma. Cancer 1998, 82(7): 1296-1302.

35. Sjostrom J, Krajewski S, Franssila K, Niskanen E, Wasenius VM, Nordling S, Reed JC, Blomqvist C: A multivariate analysis of tumour biological factors predicting response to cytotoxic treatment in advanced breast cancer. $\mathrm{Br} J$ Cancer 1998, 78(6):8|2-8I5.

36. Zhang GJ, Tsuda H, Adachi I, Fukutomi T, Yamamoto H, Hirohashi S: Prognostic indicators for breast cancer patients with one to three regional lymph node metastases, with special reference to alterations in expression levels of bcl-2, p53 and cerbB-2 proteins. Jpn / Clin Oncol 1997, 27(6):37I-377.
37. Elledge RM, Green S, Howes L, Clark GM, Berardo M, Allred DC, Pugh R, Ciocca D, Ravdin P, O'Sullivan J, Rivkin S, Martino S, Osborne CK: bcl-2, p53, and response to tamoxifen in estrogen receptor-positive metastatic breast cancer: a Southwest Oncology Group study. J Clin Oncol 1997, I 5(5):1916-1922.

38. Silvestrini R, Benini E, Veneroni S, Daidone MG, Tomasic G, Squicciarini $\mathrm{P}$, Salvadori B: p53 and bcl-2 expression correlates with clinical outcome in a series of node-positive breast cancer patients. J Clin Oncol 1996, I4(5): 1604-1610.

39. Hellemans P, van Dam PA, Weyler J, van Oosterom AT, Buytaert P, Van Marck E: Prognostic value of bcl-2 expression in invasive breast cancer. Br J Cancer 1995, 72(2):354-360.

40. Gasparini G, Barbareschi M, Doglioni C, Palma PD, Mauri FA, Boracchi P, Bevilacqua P, Caffo O, Morelli L, Verderio P, et al.: Expression of bcl-2 protein predicts efficacy of adjuvant treatments in operable node-positive breast cancer. Clin Cancer Res 1995, I(2): $189-198$

4I. Silvestrini R, Veneroni S, Daidone MG, Benini E, Boracchi P, Mezzetti M, Di Fronzo G, Rilke F, Veronesi U: The Bcl-2 protein: a prognostic indicator strongly related to $\mathrm{p} 53$ protein in lymph node-negative breast cancer patients. J Natl Cancer Inst 1994, 86(7):499-504.

42. Parmar MK, Torri V, Stewart L: Extracting summary statistics to perform meta-analyses of the published literature for survival endpoints. Stat Med 1998, I 7(24):28I5-2834.

43. Lee WY, Su WC, Lin PW, Guo HR, Chang TW, Chen HH: Expression of SI OOA4 and Met: potential predictors for metastasis and survival in early-stage breast cancer. Oncology 2004, 66(6):429-438.

44. Lipponen P, Pietilainen T, Kosma VM, Aaltomaa S, Eskelinen M, Syrjanen $\mathrm{K}$ : Apoptosis suppressing protein bcl-2 is expressed in well-differentiated breast carcinomas with favourable prognosis. J Pathol 1995, 177( (1):49-55.

45. Charpin C, Garcia S, Bonnier P, Martini F, Andrac L, Horschowski N, Lavaut MN, Allasia C: Bcl-2 automated quantitative immunocytochemical assays in breast carcinomas: correlation with 10 year follow-up. J Clin Oncol 1998, 16(6):2025-203I.

46. Kapranos N, Karaiosifidi H, Valavanis C, Kouri E, Vasilaros S: Prognostic significance of apoptosis related proteins $\mathrm{Bcl}-2$ and Bax in node-negative breast cancer patients. Anticancer Res 1997, 17(4A):2499-2505.

47. McCallum M, Baker C, Gillespie K, Cohen B, Stewart H, Leonard R, Cameron D, Leake R, Paxton J, Robertson A, Purdie C, Gould A, Steel $M$ : A prognostic index for operable, node-negative breast cancer. Br J Cancer 2004, 90( I 0):1933-194I.

48. Veronese S, Mauri FA, Caffo O, Scaioli M, Aldovini D, Perrone G, Galligioni E, Doglioni C, Dalla Palma P, Barbareschi M: Bax immunohistochemical expression in breast carcinoma: a study with long term follow-up. Int J Cancer 1998, 79(1):13-18.

49. Bhatavdekar JM, Patel DD, Shah NG, Vora HH, Suthar TP, Chikhlikar PR, Ghosh N, Trivedi TI: Prognostic significance of immunohistochemically localized biomarkers in stage II and stage III breast cancer: a multivariate analysis. Ann Surg Oncol 2000, 7(4):305-3II.

50. Al-Moundhri M, Nirmala V, Al-Mawaly K, Ganguly S, Burney I, Rizvi A, Grant C: Significance of p53, Bcl-2, and HER-2/neu protein expression in Omani Arab females with breast cancer. Pathol Oncol Res 2003, 9(4):226-23I.

5I. Abdulkader I, Sanchez L, Cameselle-Teijeiro J, Gude F, Chavez JE, Lopez-Lopez R, Forteza J, Fraga M: Cell-cycle-associated markers and clinical outcome in human epithelial cancers: a tissue microarray study. Oncol Rep 2005, I 4(6):|527-|53|.

52. Linjawi $A$, Kontogiannea M, Halwani F, Edwardes M, Meterissian S: Prognostic significance of p53, bcl-2, and Bax expression in early breast cancer. J Am Coll Surg 2004, 198(I):83-90.

53. Koukourakis MI, Giatromanolaki A, Galazios G, Sivridis E: Molecular analysis of local relapse in high-risk breast cancer patients: can radiotherapy fractionation and time factors make a difference? Br J Cancer 2003, 88(5):71I-717.

54. DerSimonian R, Laird N: Meta-analysis in clinical trials. Control Clin Trials 1986, 7(3): I77-I88.

55. Higgins JP, Thompson SG, Deeks J], Altman DG: Measuring inconsistency in meta-analyses. Bmj 2003, 327(74|4):557-560.

56. Egger M, Davey Smith G, Schneider M, Minder C: Bias in metaanalysis detected by a simple, graphical test. Bmj 1997, 3 I 5(7 | 09):629-634. 
57. Zinkel S, Gross A, Yang E: BCL2 family in DNA damage and cell cycle control. Cell Death Differ 2006, I3(8):135|-1359.

58. Carroll JS, Meyer CA, Song J, Li W, Geistlinger TR, Eeckhoute J, Brodsky AS, Keeton EK, Fertuck KC, Hall GF, Wang Q, Bekiranov S, Sementchenko V, Fox EA, Silver PA, Gingeras TR, Liu XS, Brown M: Genome-wide analysis of estrogen receptor binding sites. Nat Genet 2006, 38(I I): I289-1297.

59. Feldman M, Stanford R, Catcheside A, Stotter A: The use of a prognostic table to aid decision making on adjuvant therapy for women with early breast cancer. Eur J Surg Oncol 2002, 28(6):615-619.

60. Blamey RW, Ellis IO, Pinder SE, Lee AH, Macmillan RD, Morgan DA Robertson JF, Mitchell MJ, Ball GR, Haybittle JL, Elston CW: Survival of invasive breast cancer according to the Nottingham Prognostic Index in cases diagnosed in 1990-1999. Eur J Cance 2007, 43(10): 1548-1555.

6I. Daidone MG, Luisi A, Veneroni S, Benini E, Silvestrini R: Clinical studies of Bcl-2 and treatment benefit in breast cancer patients. Endocr Relat Cancer 1999, 6(1):61-68.

62. Wang TT, Phang JM: Effects of estrogen on apoptotic pathways in human breast cancer cell line MCF-7. Cancer Res 1995 55(I 2):2487-2489.

63. Cardoso F, Paesmans M, Larsimont D, Durbecq V, Bernard-Marty $C$ Rouas G, Dolci S, Sotiriou C, Piccart MJ, Di Leo A: Potential predictive value of $\mathrm{Bcl}-2$ for response to tamoxifen in the adjuvant setting of node-positive breast cancer. Clin Breast Cancer 2004, 5(5):364-369.

\section{Pre-publication history}

The pre-publication history for this paper can be accessed here:

http://www.biomedcentral.com/1471-2407/8/153/pre pub

Publish with Bio Med Central and every scientist can read your work free of charge

"BioMed Central will be the most significant development for disseminating the results of biomedical research in our lifetime. "

Sir Paul Nurse, Cancer Research UK

Your research papers will be:

- available free of charge to the entire biomedical community

- peer reviewed and published immediately upon acceptance

- cited in PubMed and archived on PubMed Central

- yours - you keep the copyright 